\title{
Comparison of stem cells from human exfoliated deciduous posterior teeth with varying levels of root resorption
}

\author{
Meghna Bhandary ${ }^{1}$, Shama Rao ${ }^{2}$, Alandur Veena Shetty ${ }^{2}$, Basavarajappa Mohana Kumar ${ }^{2}$, \\ Amitha Mahesh Hegde ${ }^{1}$, Rachaita Chhabra ${ }^{1}$
}

${ }^{1}$ Department of Pediatric and Preventive Dentistry, A. B. Shetty Memorial Institute of Dental Sciences, Nitte University (Deemed to be University), Mangaluru, India; ${ }^{2}$ Nitte University Centre for Stem Cell Research and Regenerative Medicine, K. S. Hegde Medical Academy, Nitte University (Deemed to be University), Mangaluru, India

Contributions: (I) Conception and design: M Bhandary, BM Kumar, AM Hegde; (II) Administrative support: AM Hegde, AV Shetty; (III) Provision of study materials or patients: M Bhandary, R Chhabra, AM Hegde; (IV) Collection and assembly of data: M Bhandary, S Rao; (V) Data analysis and interpretation: M Bhandary, S Rao, BM Kumar; (VI) Manuscript writing: All authors; (VII) Final approval of manuscript: All authors.

Correspondence to: Dr. Amitha Mahesh Hegde, Sr. Professor and Head, Department of Pediatric and Preventive Dentistry, A. B. Shetty Memorial Institute of Dental Sciences, Nitte University (Deemed to be University), Deralakatte-575018, Mangaluru, India. Email: amipedo9@gmail.com; Dr. Meghna Bhandary. Senior Lecturer, Department of Pediatric and Preventive Dentistry, A. B. Shetty Memorial Institute of Dental Sciences, Nitte University (Deemed to be University), Deralakatte-575018, Mangaluru, India. Email: drmeghna@nitte.edu.in.

Background: Stem cells from human exfoliated deciduous teeth (SHED) are regarded as an attractive cell source for tissue regeneration. However, the effect of different levels of root resorption on the characteristics of SHED remains less understood. Thus, the tooth source that is most suitable for the isolation of SHEDs needs to be determined. To compare cellular and biological characteristics of stem cells from human exfoliated deciduous posterior teeth with varying levels of root resorption.

Methods: The pulp was obtained from the deciduous posterior teeth depending on the level of root resorption, and isolated SHEDs were grouped as follows: Teeth with 0 to $1 / 3^{\text {rd }}$ root resorption as SHEDs (G1) and $1 / 3^{\text {rd }}$ to $2 / 3^{\text {rd }}$ root resorption as SHEDs (G2). Teeth were also collected from $>2 / 3^{\text {rd }}$ root resorption status, but failed to establish primary culture of SHED as the availability of pulp tissue was too less. Later, isolated SHEDs were compared on their morphology, viability, growth kinetics, colony-forming ability, expression of cell surface markers and in vitro differentiation into osteocytes and adipocytes.

Results: No major differences were observed in terms of cellular morphology, viability, proliferation rate, colony-forming ability, cell surface markers expression, and mesenchymal lineage differentiation of SHEDs isolated from posterior teeth with 0 to $1 / 3^{\text {rd }}$ and $1 / 3^{\text {rd }}$ to $2 / 3^{\text {rd }}$ root resorption. However, SHED from teeth with 0 to $1 / 3^{\text {rd }}$ root resorption $(\mathrm{G} 1)$ displayed relatively higher proliferation capacity and expression of selected markers.

Conclusions: Collectively, SHEDs (G1) and SHEDs (G2) showed comparable cellular and biological characteristics that enable their possible applications in regenerative therapies.

Keywords: Stem cells from human exfoliated deciduous posterior teeth; root resorption; markers expression; differentiation; in vitro culture

Received: 26 August 2020; Accepted: 17 May 2021; Published: 16 August 2021.

doi: $10.21037 /$ sci-2020-039

View this article at: http://dx.doi.org/10.21037/sci-2020-039

\section{Introduction}

Human dental stem cells (DSCs) have been considered as promising autologous source for cell-based therapies and tissue engineering applications due to their self-renewal capabilities and multi-lineage differentiation potentials (1). Dental pulp stem cells (DPSCs) from impacted third molars 
were first discovered by Gronthos et al. in 2000 (2); and later, stem cells from human exfoliated deciduous teeth (SHED) were first isolated by Miura et al. 2003 (3). SHEDs offer a unique population because of more accessibility and ease of collection as a clinically and biologically discarded postnatal tissue with limited ethical concerns $(4,5)$.

As a type of multipotent mesenchymal stem/stromal cells (MSCs), SHED possessed features of more immature multipotent cells, including greater proliferation rate, shorter population doubling time (PDT) and enhanced osteoinductive capacity when compared to DPSCs (6-10). In addition, these cells were able to induce bone tissue formation and dentin generation following their in vivo transplantation into mouse tissues $(11,12)$. Further, a recent study showed that implantation of autologous human deciduous pulp stem cells in patients undergoing trauma regenerated the lost three-dimensional pulp tissue, restored pulp function and stimulated root development. These findings indicated that SHED could be an ideal source of stem cells for tissue engineering (13).

Both DPSCs and SHEDs have been demonstrated with largely similar features of MSCs under in vitro culture conditions. But, differences in biological characteristics exist owing to variations in anatomical localizations and dynamic processes at tissue microenvironment (14). The major characteristic difference between the pulp of primary and permanent teeth is the occurrence of physiologic root resorption and mixed dentition stages of the deciduous teeth (15). It was suggested that the pulp acquired from deciduous teeth without root resorption did not support the derivation of viable cell lines in comparison to those from teeth with resorbed roots (15). Although the detailed biological properties of SHED are being rigorously investigated $(5,16,17)$, the effect of different levels of root resorption on the characteristics of cell lines obtained from these teeth remains inconclusive. Thus, the tooth source that is most suitable for the isolation of SHEDs needs to be determined.

To understand the potency of stem cells derived from deciduous posterior teeth (SHEDs) with varying levels of root resorption, the present study compared their morphology, viability, proliferation rate and PDT, colonyforming ability, expression of cell surface markers and in vitro differentiation potential into osteocytes and adipocytes. Advancement in cellular and biological characterization of SHEDs based on root resorption status will enable the clinicians with suitable cell-source for tissue regeneration.

We present the following article in accordance with the MDAR reporting checklist (available at http://dx.doi. org/10.21037/sci-2020-039).

\section{Methods}

\section{Sample collection}

Clinically healthy exfoliated deciduous posterior teeth were obtained from children aged 7-14 years as a part of the treatment plan visiting Department of Pedodontics and Preventive Dentistry at AB Shetty Memorial Institute of Dental Sciences (ABSMIDS). Ethical clearance was obtained from the Institutional Ethical Committee, ABSMIDS, and Institutional Committee for Stem Cell Research (ICSCR), Nitte (Deemed to be University), Mangaluru (Cert No.: ABSM/EC55/2016 dated 18/10/2016). The study was conducted in accordance with the Declaration of Helsinki (as revised in 2013). Informed consent was taken from all the individual participants. The teeth were examined clinically to assess the zones of root resorption and classified based on the maximal root wall present. Teeth with decay, pulpal necrosis and h/o trauma were excluded. The pulp was then obtained from the deciduous posterior teeth depending on the level of root resorption, and isolated SHEDs were grouped as follows: Teeth with 0 to $1 / 3^{\text {rd }}$ root resorption as SHEDs (G1) (n=3) and $1 / 3^{\text {rd }}$ to $2 / 3^{\text {rd }}$ root resorption as SHEDs (G2) $(n=3)$. Teeth were also collected from $>2 / 3^{\text {rd }}$ root resorption status $(\mathrm{n}=3)$, but failed to establish primary culture of SHED as the availability of pulp tissue was too less.

\section{Isolation and culture of SHED}

The harvested pulp tissue was rinsed with Dulbecco's phosphate-buffered saline (DPBS) (Gibco, Life Technologies, Thermo Fisher Scientific, USA) containing antibiotics and antimycotic solutions, including penicillin, streptomycin (Pen-Strep, 1\% solution, Gibco) and amphotericin-B (Gibco) and minced into fragments of $0.5-1 \mathrm{~mm}^{3}$. Fragmented pulp tissues were then digested in a mixture of $0.1 \%$ collagenase I (Gibco) in $\alpha$-minimum essential medium ( $\alpha$-MEM, Gibco) for $30 \mathrm{~min}$ at $37^{\circ} \mathrm{C}$ in a $\mathrm{CO}_{2}$ incubator. After the partial enzymatic digestion, the cell aggregates were removed by passing through $70 \mu \mathrm{M}$ cell strainers (BD Falcon, USA) and centrifuged at 1,200 rpm for $5 \mathrm{~min}$. The cell suspension was seeded and the explants were placed on plastic tissue culture dishes containing $\alpha$-MEM supplemented with $10 \%$ fetal bovine serum 
(FBS, Gibco), $2.5 \mu \mathrm{g} / \mathrm{mL}$ of amphotericin B, $100 \mathrm{U} / \mathrm{mL}$ of penicillin and $100 \mu \mathrm{g} / \mathrm{mL}$ of streptomycin (Gibco) and incubated at $37{ }^{\circ} \mathrm{C}$ in a humidified atmosphere of $5 \% \mathrm{CO}_{2}$ in air. After $48 \mathrm{~h}$, unattached cells were removed by changing the medium. After 15 days, when the cells reached almost confluency, SHEDs were detached using $0.25 \%$ trypsinethylenediaminetatraacetic acid (EDTA) (Gibco) and subcultured. All assays were carried out by using SHEDs at passages 2-5.

\section{Morphology and viability analyses}

SHEDs were assessed for morphology using a phasecontrast microscope (Olympus, Japan). Before analysis, they were gently washed with DPBS to remove cells in suspension and subjected for photomicrography. The viability of SHEDs was assessed in triplicates for each cell line using $0.4 \%$ trypan blue (Gibco). The stained cells were counted in a haemocytometer with an inverted phasecontrast microscope (Olympus).

\section{Cell proliferation assay and PDT}

SHEDs were seeded into 12 -well culture plates (Nunc, Thermo Fisher Scientific, USA) at a density of $1 \times 10^{3} /$ well with $\alpha$-MEM containing $10 \% \mathrm{FBS}, 100 \mathrm{U} / \mathrm{mL}$ of penicillin and $100 \mu \mathrm{g} / \mathrm{mL}$ of streptomycin and incubated at $37{ }^{\circ} \mathrm{C}$ in $5 \% \mathrm{CO}_{2}$. Cell proliferation was determined in triplicates by counting the cells using a hemocytometer on days 3 , 6, 9 and 12 under a phase-contrast microscope (Olympus, Japan). PDT was calculated using the formula; PDT $=\mathrm{t}(\log$ 2)/(log Nt - $\log$ No), where $t$ indicates culture time, No and $\mathrm{Nt}$ represent the cell number before and after seeding, respectively.

\section{Colony-forming unit (CFU) assay}

The CFUs assay was performed to determine the presence of putative stem cells in the isolated SHEDs. Cells were plated at $1 \times 10^{3} /$ well onto $35 \mathrm{~mm}$ culture dishes with growth medium for 12 days. Then, the cells were fixed with $3.7 \%$ paraformaldehyde (Sigma-Aldrich, USA) and stained with crystal violet (Sigma-Aldrich) for imaging with an inverted phase-contrast microscope (Olympus).

\section{Flow cytometry analysis of cell surface markers}

SHEDs at $80 \%$ confluence were harvested and fixed with
3.7\% paraformaldehyde (Sigma-Aldrich, USA) for $30 \mathrm{~min}$. The cells were subsequently incubated with different antibodies, including CD73 (Biolegend, USA, 1:100), CD90 (E-bioscience, USA, 1:100), CD105 (Biolegend, 1:100) CD34 (Biolegend, 1:100) and CD45 (E-bioscience, $1: 100$ ) for $2 \mathrm{~h}$ at $37^{\circ} \mathrm{C}$. Fluorescein isothiocyanate (FITC)conjugated anti-mouse IgG (E-bioscience, 1:100) was used as a secondary antibody and stained for $1 \mathrm{~h}$ at room temperature. Matching isotypes were used as negative controls. After being washed with DPBS, the cells were analyzed with flow cytometer (FACSCalibur, Becton Dickinson, USA). A total of 10,000 events were acquired and analyzed with Cell Quest software (Becton Dickinson).

\section{Osteogenic differentiation}

SHEDs were plated at a density of $1 \times 10^{4} \mathrm{cells} / \mathrm{cm}^{2}$ and cultured in maintenance medium consisting of $\alpha-M E M$ with $10 \%$ FBS. When the cells reached $70 \%$ confluence, the culture media was replaced with osteogenic medium consisting of $\alpha$-MEM supplemented with $10 \%$ FBS, $0.1 \mu \mathrm{M}$ dexamethasone (Sigma-Aldrich), $10 \mathrm{mM}$ sodium $\beta$-glycerophosphate (Sigma-Aldrich) and $100 \mu \mathrm{M}$ ascorbic acid (Sigma-Aldrich). The cultures were maintained for 3 weeks and media was changed twice a week. Control cultures were sustained with basal medium. For staining, the cultured cells were fixed with $3.7 \%$ paraformaldehyde (Sigma-Aldrich) at room temperature and stained with $40 \mathrm{mM}$ Alizarin Red S (pH 4.2) for $30 \mathrm{~min}$. The plates were rinsed three times with DPBS to remove excess stain and then observed using an inverted phase-contrast microscope (Olympus).

\section{Adipogenic differentiation}

SHEDs were plated at a density of $1 \times 10^{4}$ cells $/ \mathrm{cm}^{2}$ and cultured in maintenance medium consisting of $\alpha$-MEM with $10 \%$ FBS. When the cells reached $70 \%$ confluence, the culture media was replaced with adipogenic medium consisting of $\alpha$-MEM supplemented with $10 \%$ FBS, $10 \mu \mathrm{M}$ insulin (Sigma-Aldrich), $200 \mu \mathrm{M}$ indomethacin (SigmaAldrich), $500 \mu \mathrm{M}$ isobutyl-methylxanthine (Sigma-Aldrich) and $1 \mu \mathrm{M}$ dexamethasone (Sigma-Aldrich). The cultures were maintained for 3 weeks and media was changed twice a week. Cells in control were cultured with basal medium. Adipocyte differentiation was confirmed with Oil red O (Sigma-Aldrich). The procedure involved the washing of cells thrice in DPBS and fixing them for $30 \mathrm{~min}$ in $3.7 \%$ 

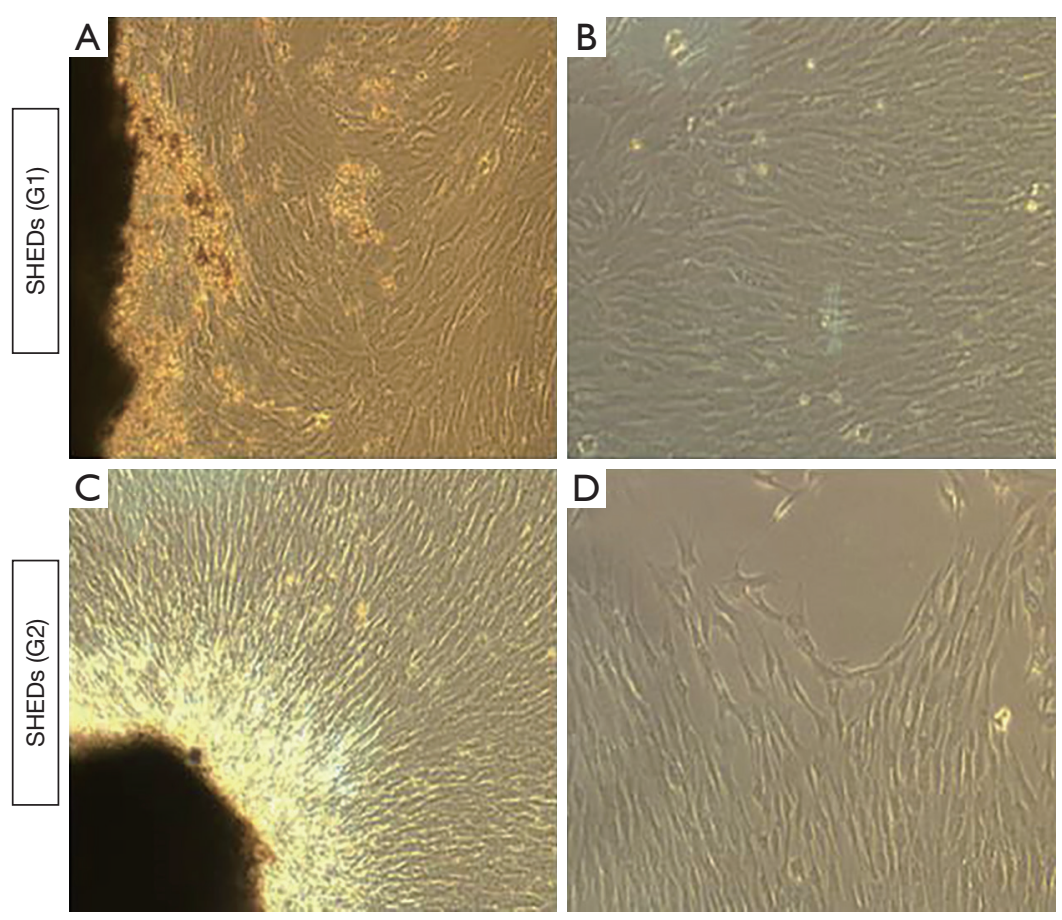

Figure 1 Morphology of SHEDs using trypan blue under a phase-contrast microscope. (A) Outgrowth of cells from the pulp tissue explant in SHEDs (G1) and adherence to plastic dish in primary culture. Magnification $\times 40$. (B) On $15^{\text {th }}$ day of primary culture, more number of cells attached and attained a characteristic fibroblastic morphology. Magnification $\times 40$. (C) Release of cells from tissue remnant in SHEDs (G2). Magnification $\times 40$. (D) Fibroblast-like morphology was observed in cells by day 15 of primary culture. Magnification $\times 40$. SHED, stem cells from human exfoliated deciduous teeth.

paraformaldehyde (Sigma-Aldrich). The plates were rinsed three times with DPBS to remove non-adherent cells and stained with Oil red O solution for $10 \mathrm{~min}$. Cells were washed and excess dye was subsequently removed with $70 \%$ ethanol. They were then observed using an inverted phasecontrast microscope (Olympus) for fat deposition.

\section{Statistical analysis}

All experiments were performed at least in triplicates. The data were expressed as the mean \pm SD values. Analysis of variance (ANOVA) was performed using GraphPad Prism software (GraphPad, CA, USA) with Tukey's post-hoc tests. The level of statistical significance was set at $\mathrm{P}<0.05$.

\section{Results}

\section{Isolation and culture of SHEDs}

Isolation of SHEDs was successful in three samples each collected from posterior teeth with 0 to $1 / 3^{\text {rd }}$ root resorption and $1 / 3^{\text {rd }}$ to $2 / 3^{\text {rd }}$ root resorption. Tissue explants were firmly adhered onto the plastic culture dishes and initial out-growth of SHEDs was observed by $4^{\text {th }}$ day of primary culture. By $15^{\text {th }}$ day of primary culture, a monolayer of cells with $90 \%$ confluency was observed in both SHEDs (G1) and SHEDs (G2) (Figure 1A,B,C,D).

\section{Morphology and viability of SHEDs}

Isolated SHEDs displayed typical fibroblast-like morphology (Figure 1A,B,C,D). A small number of cells were spindle-shaped, polygonal or elongated, but disappeared during the later stages of cell culture. After passaging, the cells were attached onto the culture dishes within $12 \mathrm{~h}$ and reached $90 \%$ confluence within 2 weeks. Sub-cultured cells gradually became flattened and they too acquired a fibroblast-like morphology exhibiting a more homogenous population of cells up to fifth passage without any variations in morphological features between 

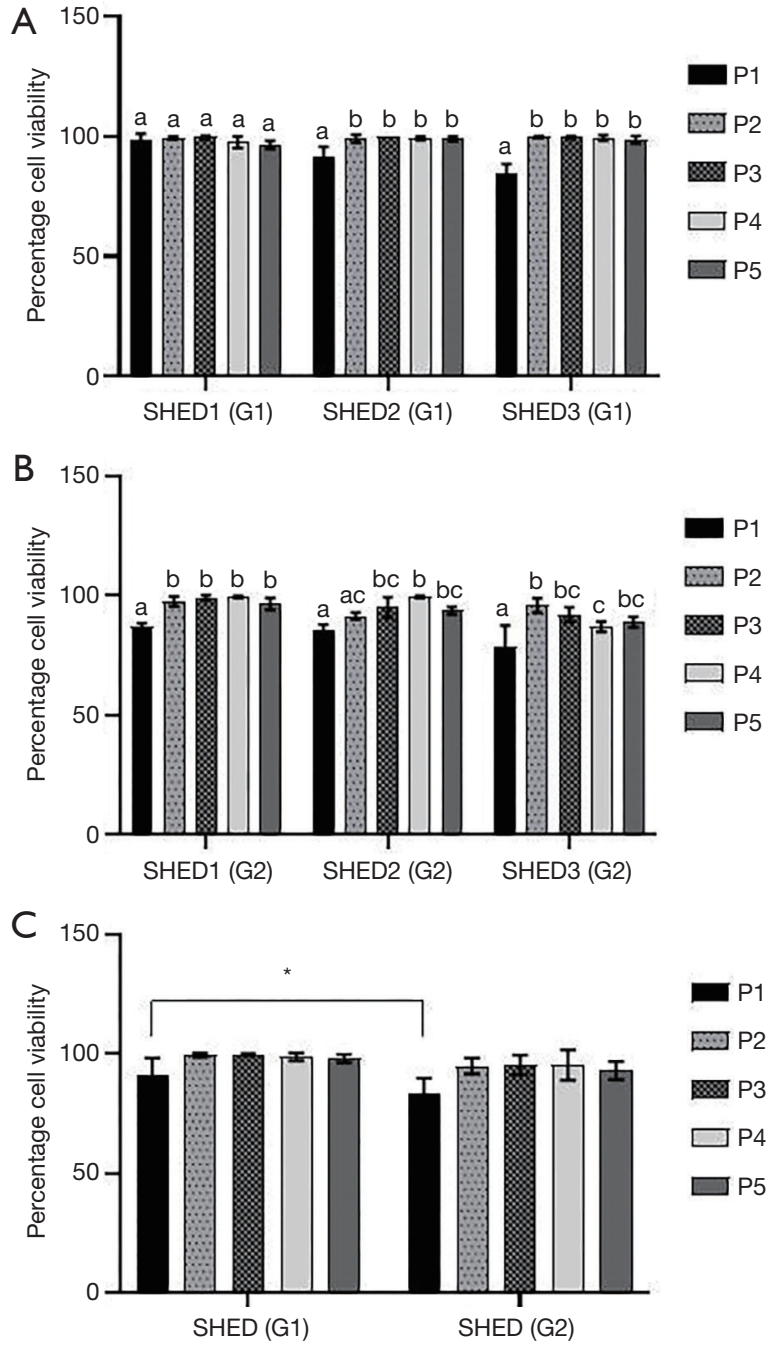

Figure 2 Viability of SHEDs. (A) Viability of SHEDs (G1) and (B) SHEDs (G2). (C) Comparison of viability between SHEDs (G1) and SHEDs (G2). Percentage values are represented as mean \pm standard deviation (SD). Superscripts a, b, c and * indicate significant differences at $\mathrm{P}<0.05$. SHED, stem cells from human exfoliated deciduous teeth.

SHEDs (G1) and SHEDs (G2). The viability of SHEDs was assessed using trypan blue dye exclusion assay. Except at passage 1, viability of SHEDs (G1) was recorded above $90 \%$ at different time point of analysis (Figure $2 A$ ). In SHEDs (G2), viability was slightly lower at passage 1 . But, at later passages, viability was found increased and had values more than $90 \%$ in all SHEDs (Figure 2B). A significant difference $(\mathrm{P}<0.05)$ in viability was observed at passage 1 between SHEDs (G1) and SHEDs (G2) (Figure 2C). However, no significant differences were noted at other passages.

\section{Growth kinetics and PDT of SHEDs}

Rate of proliferation in all cell lines of SHEDs (G1) (Figure $3 A$ ) and SHEDs (G2) (Figure 3B) was high during the culture period of 12 days. Despite this similarity, minimal differences were observed between the cell lines in both groups of SHED. Proliferation was initially similar, but after 3 days, it appeared to be slightly higher in SHEDs (G1) than for SHEDs (G2) (Figure 3C). A significant difference $(\mathrm{P}<0.05)$ in cell numbers was observed at different time points of culture, particularly on days 6,9 and 12. Consistent to this observation, SHEDs (G1) showed a significantly $(\mathrm{P}<0.05)$ lower PDT $(54.41 \mathrm{~h})$ than in SHEDs (G2) (67.81 h) (Figure 3D).

\section{CFU assay of SHEDs}

All the three cell lines from SHEDs (G1) and SHEDs (G2) demonstrated their distinctive feature of colonyforming ability (Figure 4) after 12 days of culture. The size of the colonies formed in SHEDs (G1) (Figure 4A,B,C) appeared to be slightly larger in comparison to SHEDs (G2) (Figure 4D,E,F). But, no noticeable differences were observed in terms of the number of CFUs.

\section{Cell surface marker analysis of SHEDs}

Stem cell surface markers were assessed in SHEDs using flow cytometry and the representative images are presented in Figure 5. The results showed that SHEDs (G1) and SHEDs (G2) maintained the characteristic phenotype of MSCs by positive expression of markers, such as CD73, CD90 and CD105. However, the SHEDs were negative for CD34 and CD45, which are considered as the markers of hematopoietic stem cells. SHEDs (G1) showed the mean expression of CD73 (71.64\%), CD90 (59.85\%), and CD105 $(33.57 \%)$, and were negative for CD34 (0.62\%) and CD45 $(0.38 \%)$ markers. Similarly, SHEDs (G2) also displayed the mean positive expression for CD73 (83.74\%), CD90 (95.56\%), and CD105 (60.84\%), and were negative for CD34 (0.78\%) and CD45 (0.21\%) markers.

\section{Osteogenic differentiation}

Osteogenic differentiation ability of SHEDs from both groups were assessed by culturing the cells in osteogenic induction medium for 3 weeks. The images of osteogenic differentiation in SHEDs are presented in Figure $6 A, B$. 

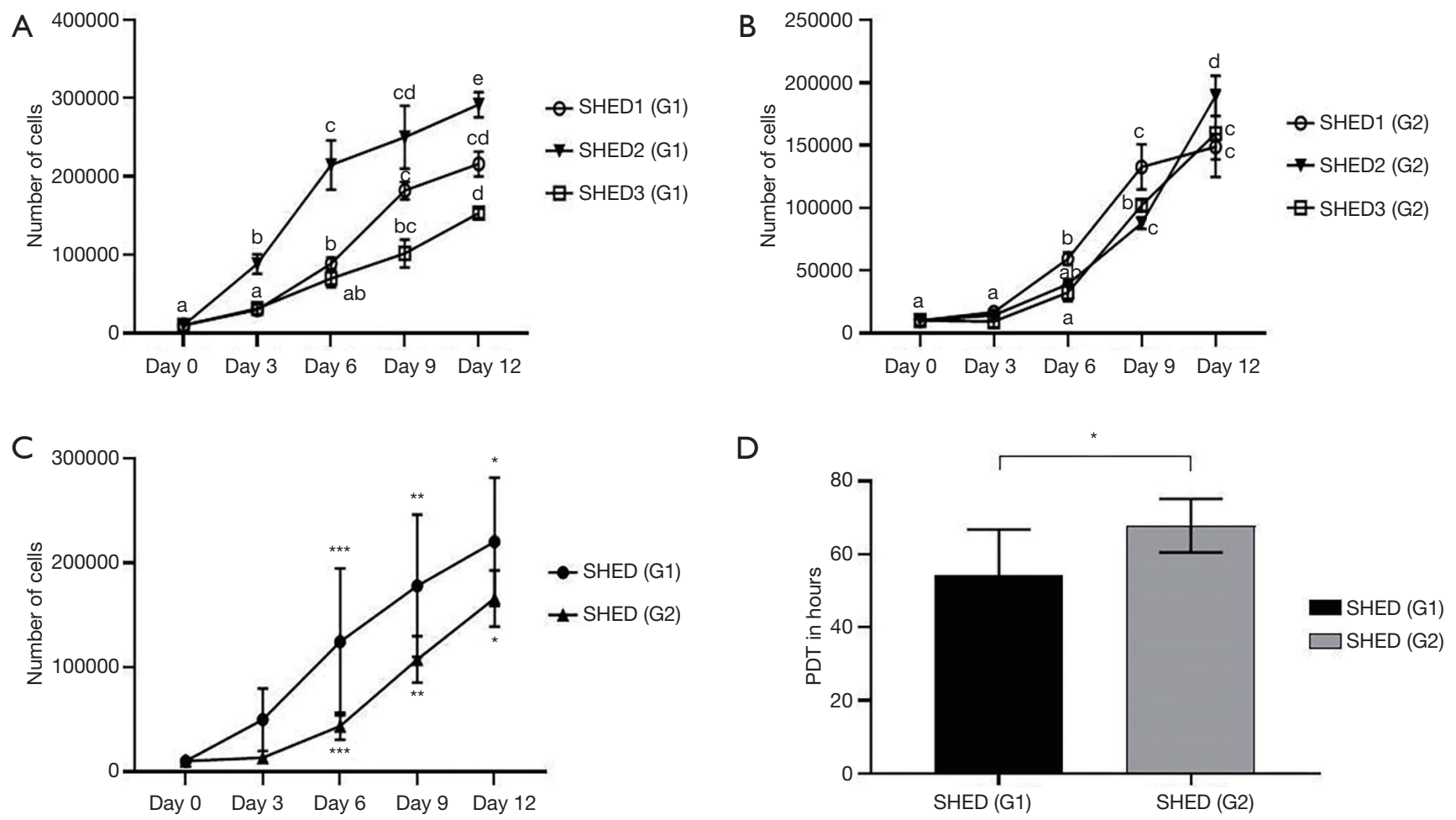

Figure 3 Proliferation rate and PDT of SHEDs. Rate of proliferation in (A) SHEDs (G1) and (B) SHEDs (G2). (C) Comparison of proliferation rates between SHEDs (G1) and SHEDs (G2). (D) PDT in hours among SHEDs (G1) and SHEDs (G2). Superscripts a, b, c, d, e and *,**,** indicate significant difference $(\mathrm{P}<0.05)$ at the given time point of analysis. PDT, population doubling time; SHED, stem cells from human exfoliated deciduous teeth.

Cells without osteogenic induction medium (control) showed fibroblast-like morphology even after 3 weeks of culture in SHEDs (G1) (Figure 6A-a) and SHEDs (G2) (Figure 6B-a). On the contrary, Alizarin red $\mathrm{S}$ staining clearly demonstrated the deposition of calcified matrix in SHEDs (G1) (Figure 6A$b, c \& d$ ) and SHEDs (G2) (Figure $6 B-b, c \& d$ ). The staining pattern of mineralised nodules appeared to be similar in both SHEDs (G1) and SHEDs (G2).

\section{Adipogenic differentiation}

Adipogenic differentiation ability of SHEDs from both groups were evaluated by inducing the cells in adipogenic medium for 3 weeks. The results of adipogenic differentiation in SHEDs are presented in Figure $7 A, B$. No adipogenesis was observed in the control SHEDs (G1) (Figure $7 A-a$ ) and SHEDs (G2) (Figure 7B-a). However, the Oil red $\mathrm{O}$ staining showed the accumulation of lipid droplets in SHEDs (G1) (Figure $7 A-b, c \& d$ ) and SHEDs (G2) (Figure $7 B-b, c \& d$ ). The staining pattern in both groups was comparable. SHEDs in induction medium showed the progressive loss of the fibroblastoid-like shape and the production of large number of cytoplasmic lipid vacuoles.

\section{Discussion}

The present study compared the cellular, phenotypic and biological properties of SHEDs isolated from posterior teeth with varying levels of root resorption. Isolated SHEDs (G1) and SHEDs (G2) were assessed on the basis of their morphology, viability, proliferation rate and PDT, colony-forming ability, expression of cell surface markers and in vitro differentiation potential into osteocytes and adipocytes.

The primary cultures of stem cells from remnant pulp of exfoliated deciduous posterior teeth with varying levels of root resorption, such as 0 to $1 / 3^{\text {rd }}$ and $1 / 3^{\text {rd }}$ to $2 / 3^{\text {rd }}$ statuses were successfully established in this study. Teeth were also obtained with $>2 / 3^{\text {rd }}$ root resorption status for the 

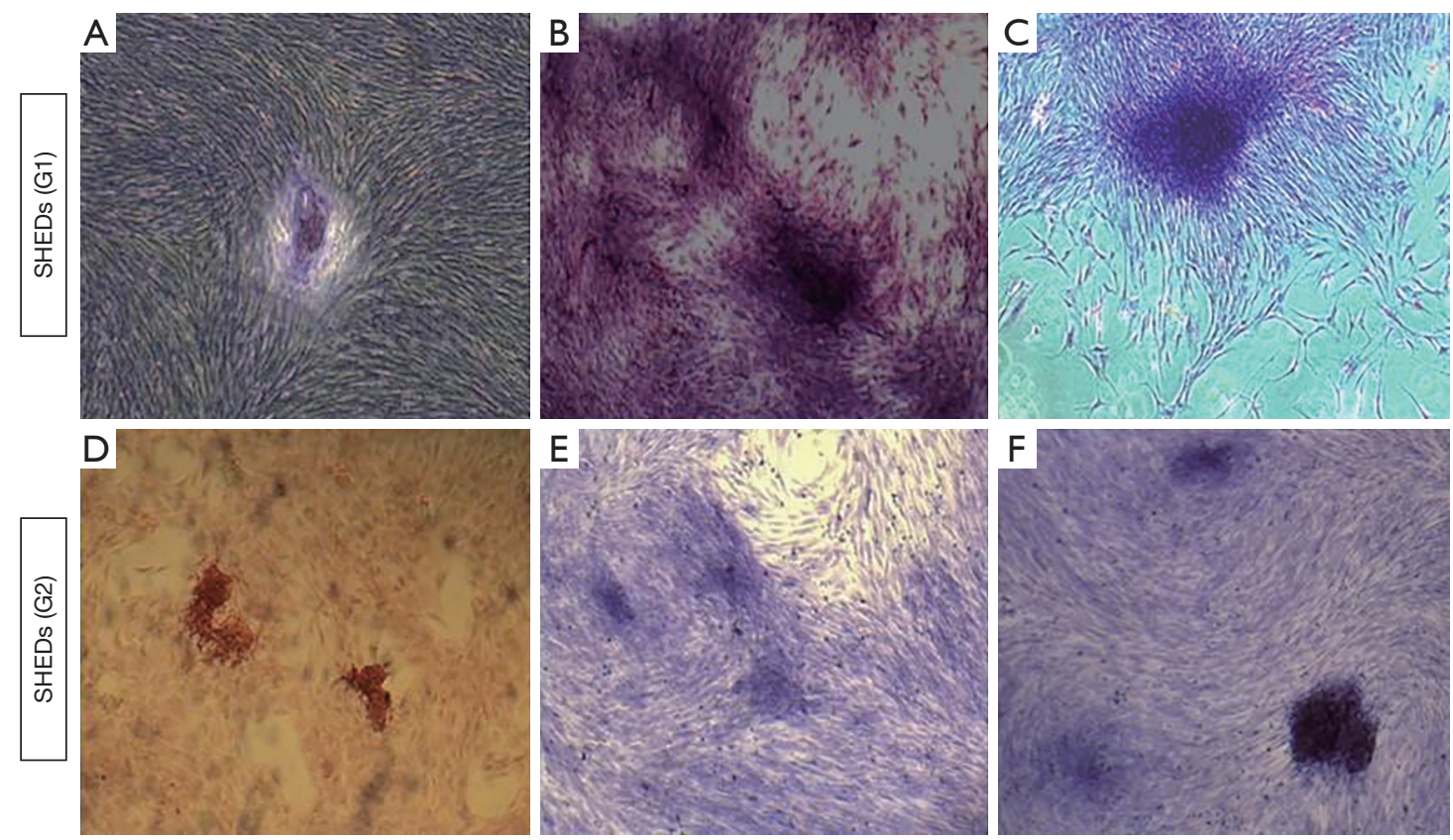

Figure 4 CFU assay of SHEDs by crystal violet staining. (A,B,C). Three cell lines from SHEDs (G1) exhibited their characteristic feature of colony-forming potency as indicated by crystal violet. Magnification $\times 40$. (D,E,F) Three cell lines from SHEDs (G2) showed their ability to form colonies as exhibited by crystal violet staining. Magnification $\times 40$. CFU, colony-forming unit; SHED, stem cells from human exfoliated deciduous teeth.
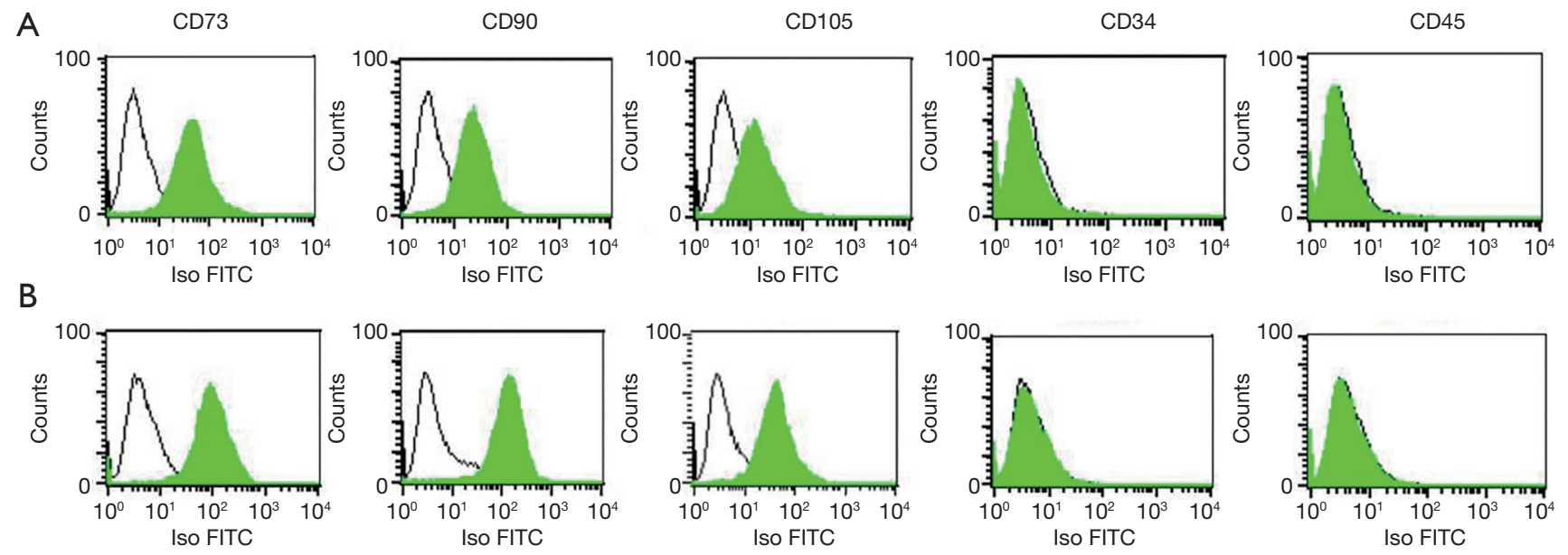

Figure 5 Flow cytometry analysis of SHEDs. (A) SHEDs (G1). (B) SHEDs (G2). The plots are showing the staining profile of selected markers (Green) and isotype control (Blank). Results revealed that SHEDs were positive for CD73, CD90 and CD105, and negative for CD34 and CD45. Data from 10,000 stained cells is presented. SHED, stem cells from human exfoliated deciduous teeth.

isolation of SHEDs. However, we could observe that the number of adhered cells during primary culture was very low as the harvested pulp tissue from teeth with $>2 / 3^{\text {rd }}$ root resorption was too less. It was perceived that the shorter root length in teeth with $>2 / 3^{\text {rd }}$ root resorption yielded a very small quantity of pulp for isolation. Extremely low cell numbers upon isolation was a shortcoming for analysis, and hence the group was discontinued. In agreement with 

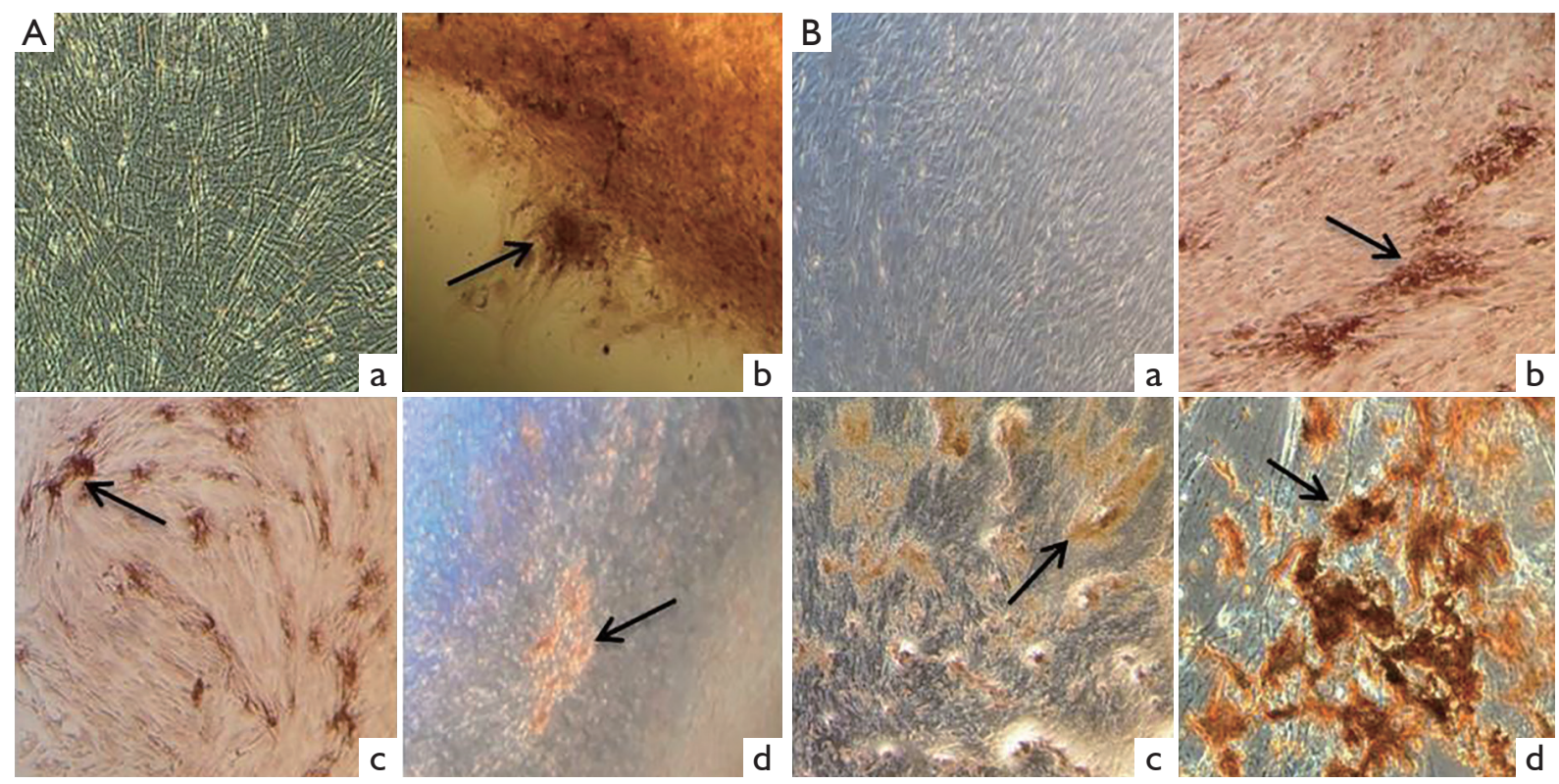

Figure 6 Osteogenic differentiation potential of SHEDs. (A) Osteogenic differentiation of SHEDs (G1) as evidenced by Alizarin red staining. a. Fibroblast-like morphology in control after Alizarin red staining. Magnification $\times 40$. b, c \& d. SHEDs (G1) differentiated towards the osteogenic lineage when cultured in osteoinductive medium for 3 weeks, as demonstrated by the deposition of calcified matrix (arrows). Magnification $\times 100$. (B) Osteogenic induction of SHEDs (G2) as indicated by Alizarin red staining. a. Control after Alizarin red staining. Magnification $\times 40$. b, c \& d. Osteogenic differentiation of SHEDs (G2) after 3 weeks showed the mineralization of calcium nodules by Alizarin red staining (arrows). Magnification $\times 100$. SHED, stem cells from human exfoliated deciduous teeth.

our observations, it was earlier opined that deciduous teeth offer a considerably lesser amount of dental pulp in comparison to third molars employed for the isolation of DPSCs (6). In addition, other related factors, such as the patient's age, length of the remaining root, and mechanical stress influence the successful isolation and establishment of SHEDs (17).

SHEDs from both groups in established cultures displayed a similar, characteristic spindle-shaped, fibroblastlike morphology. These morphological features of SHEDs are termed as immature (18), and were comparable to multipotent stem cells derived from various dental tissues $(5,7-10)$. However, the method of isolation seem to influence the cellular morphology as previously reported (19). It was observed that, enzymatic digestion of pulp tissue allowed the isolation of heterogenous cells consisting fibroblast-like cells along with the endothelial cells and pericytes $(6,19,20)$. In contrast, the explant or outgrowth method yielded a more uniform population of fibroblastlike cells $(2,8,19)$. In the present study, SHEDs were isolated from partially enzyme digested tissue which began to proliferate quite early and formed a monolayer of homogenous fibroblast-like cells for culture expansion in vitro. It is important to note that lesser enzymatic digestion is required to liberate cells, and they proliferate much better in culture. Hence, it is suggested that combination of partial enzymatic digestion and explant method could be employed to obtain suitable SHEDs.

Cell viability is an important factor when evaluating the doses for cell-based regenerative therapies. In this study, except at passage 1, the viability values observed for SHEDs in both groups were $>90 \%$ up to passage 5 . In accordance with these values, an average viability of $77.9 \%$ in the first passage (15) and $90.6 \%$ after long-term cultivation of SHEDs were recorded (21). These results collectively indicated that the isolation and expansion procedures followed had resulted in acceptable yield of viable SHEDs.

The proliferation ability of SHEDs is a critical factor for their therapeutic applications as the required number is enormously high. Our results showed that SHEDs (G1) proliferated better under identical culture conditions by exhibiting a greater replication with lower PDT values when compared with SHEDs (G2). Previous studies reported a significantly higher proliferation rate for 

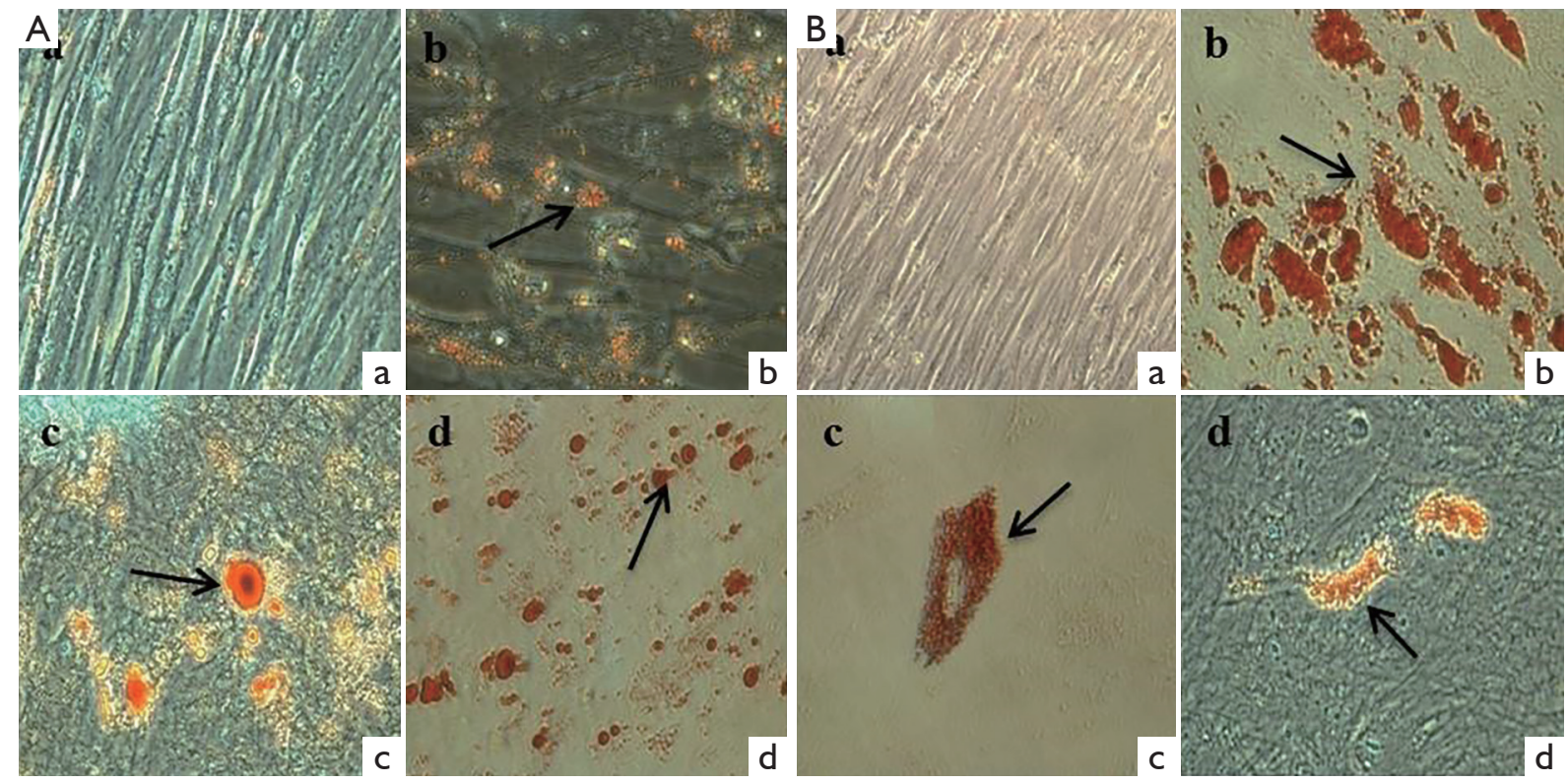

Figure 7 Adipogenic differentiation potential of SHEDs. (A) Adipogenic differentiation of SHEDs (G1) using Oil red O staining. a. Oil red $\mathrm{O}$ staining in control. Magnification $\times 100$. b, c \& d. SHEDs (G1) differentiated towards the adipogenic lineage when cultured in inductive medium for 3 weeks, as demonstrated by the deposition of fat globules (arrows). Magnification $\times 200$. (B) Adipogenic induction of SHEDs (G2) as assessed by Oil red O staining. a. Cells in control after Oil red O staining. Magnification $\times 100$. b, c \& d. Adipogenic differentiation of SHEDs (G2) after 3 weeks showed the accumulation of lipid droplets by Oil red O staining (arrows). Magnification $\times 200$. SHED, stem cells from human exfoliated deciduous teeth.

SHED to that of DPSCs and BMSCs $(6,10,14)$. Further, several investigations recorded a shorter PDT for SHEDs compared to DPSCs $(6,8,14)$. Our observations were in agreement with these findings, and SHEDs revealed their virtue of greater proliferative potential that is essential for high quantity production.

The colony-forming ability was assessed to demonstrate the clonogenic potency of SHEDs. The results exhibited that both group of SHEDs possess a largely similar and the strongest colony-forming ability after 12 days of culture. This property of SHEDs provides significant advantages in regenerative medicine. Previous studies have also observed similar colony formation ability for SHEDs, proving that these are a population of clonogenic cells with high proliferative capacity.

With regard to cell surface markers expression profile, SHEDs were positive for CD73, CD90 and CD105, while negatively expressing CD34 and CD45. The positivity of CD73, CD90 and CD105 markers expression was slightly higher in SHEDs (G2) than in SHEDs (G1). An active role of CD73 (ecto'-nucleotidase) in stromal interactions, migration ability and MSC-mediated adaptive immunity variations has been well-recognised (22). Further, CD90 (Thy1) antigen has shown to play role in cell-to-cell interactions, and also involved in adhering monocytes and leukocytes to endothelial cells and fibroblasts $(14,22)$. CD105 expression has been correlated with increased stem cell capacity in MSCs (14,22). The differential expression of above stem cell-associated markers allowed identifying a distinct population of SHEDs with enhanced selfrenewal and differentiation capacity prior to cell-based therapy. The higher expressions of these markers support the undifferentiated status and potency feature in SHEDs (7-9,14,21,23). Furthermore, in agreement with previous studies and the proposed definition of MSCs, both groups of SHEDs were negative for CD34 and CD45, confirming that the cells obtained were from mesenchymal origin $(7-9,14,21)$.

The expected plasticity for multi-lineage differentiation of SHED is vital for in vivo applications. As confirmed by Alizarin red $\mathrm{S}$ and Oil red $\mathrm{O}$ staining, the results indicated that both groups of SHEDs were equally capable of differentiating into osteocytes and adipocytes, respectively. The isolation of SHEDs by means of partially enzyme 
digestion method did not alter their mesenchymal lineage differentiation. Previously, Bakopoulou et al. [2011] opined that the isolation by enzymatic method yielded the SHEDs with a higher mineralization capacity (20). Irrespective of the method of isolation, enhanced osteogenic potential of SHEDs could make them considering as a suitable source for bone regeneration and tissue engineering, as supported by the findings of earlier in vivo studies in mice $(11,12)$. In addition, several in vitro experiments have showed the increased ability of SHEDs for osteogenic differentiation $(3,6-10)$. Further, the adipogenic differentiation potential of SHEDs was also reported (3,6-9,23). Contrastingly, a few investigations have evidenced the weaker potential or failure to undergo in vitro adipogenic differentiation by SHEDs $(5,14,16,24)$. This distinct property of SHEDs was ascribed to their pre-commitment towards the osteogenic lineage differentiation. Based on these observations, it was speculated that SHEDs may not be the appropriate source for adipose tissue replacement or regeneration.

\section{Conclusions}

In conclusion, the findings of our study revealed no major differences in cellular morphology, viability, proliferation rate, colony-forming ability, cell surface markers expression, and mesenchymal lineage differentiation of SHEDs isolated from posterior teeth with 0 to $1 / 3^{\text {rd }}$ and $1 / 3^{\text {rd }}$ to $2 / 3^{\text {rd }}$ root resorption. However, SHED from teeth with 0 to $1 / 3^{\text {rd }}$ root resorption (G1) displayed relatively higher proliferation capacity and expression of selected markers. Nevertheless, both group of SHEDs had comparable cellular and biological characteristics that enable their possible applications in regenerative therapies. In vivo experiments are still required to further assess their clinical potential.

\section{Acknowledgments}

Funding: None.

\section{Footnote}

Reporting Checklist: The authors have completed the MDAR reporting checklist. Available at http://dx.doi.org/10.21037/ sci-2020-039

Conflicts of Interest: All authors have completed the ICMJE uniform disclosure form (available at http://dx.doi. org/10.21037/sci-2020-039). The authors have no conflicts of interest to declare.

Ethical Statement: The authors are accountable for all aspects of the work in ensuring that questions related to the accuracy or integrity of any part of the work are appropriately investigated and resolved. The study was conducted in accordance with the Declaration of Helsinki (as revised in 2013). This study was approved by A.B. Shetty Memorial Institute of Dental sciences (A Constituent Unit of Nitte University) Ethical committee (Cert No.: ABSM/ EC55/2016 dated 18/10/2016). Informed consent was taken from all the individual participants.

Open Access Statement: This is an Open Access article distributed in accordance with the Creative Commons Attribution-NonCommercial-NoDerivs 4.0 International License (CC BY-NC-ND 4.0), which permits the noncommercial replication and distribution of the article with the strict proviso that no changes or edits are made and the original work is properly cited (including links to both the formal publication through the relevant DOI and the license). See: https://creativecommons.org/licenses/by-nc-nd/4.0/.

\section{References}

1. Yang JW, Shin YY, Seo Y, et al. Therapeutic functions of stem cells from oral cavity: An update. Int J Mol Sci 2020;21:e4389.

2. Gronthos S, Mankani M, Brahim J, et al. Postnatal human dental pulp stem cells (DPSCs) in vitro and in vivo. Proc Natl Acad Sci U S A 2000;97:13625-30.

3. Miura M, Gronthos S, Zhao M, et al. SHED: stem cells from human exfoliated deciduous teeth. Proc Natl Acad Sci U S A 2003;100:5807-12.

4. Rosa V, Dubey N, Islam I, et al. Pluripotency of Stem Cells from Human Exfoliated Deciduous Teeth for Tissue Engineering. Stem Cells Int 2016;2016:5957806.

5. Xie F, He J, Chen Y, et al. Multi-lineage differentiation and clinical application of stem cells from exfoliated deciduous teeth. Hum Cell 2020;33:295-302.

6. Shekar R, Ranganathan K. Phenotypic and growth characterization of human mesenchymal stem cells cultured from permanent and deciduous teeth. Indian J Dent Res 2012;23:838-9.

7. Wang X, Sha XJ, Li GH, et al. Comparative characterization of stem cells from human exfoliated deciduous teeth and dental pulp stem cells. Arch Oral Biol 2012;57:1231-40. 
8. Samiei M, Aghazadeh M, Movassaghpour AA, et al. Isolation and characterization of dental pulp stem cells from primary and permanent teeth. J Am Sci 2013;9:153-7.

9. Vishwanath VR, Nadig RR, Nadig R, et al. Differentiation of isolated and characterized human dental pulp stem cells and stem cells from human exfoliated deciduous teeth: An in vitro study. J Conserv Dent 2013;16:423-8.

10. Kunimatsu R, Nakajima K, Awada T, et al. Comparative characterization of stem cells from human exfoliated deciduous teeth, dental pulp, and bone marrow-derived mesenchymal stem cells. Biochem Biophys Res Commun 2018;501:193-8.

11. Seo BM, Sonoyama W, Yamaza T, et al. SHED repair critical-size calvarial defects in mice. Oral Dis 2008;14:428-34.

12. Sebastian AA, Kannan TP, Norazmi MN, et al. Interleukin-17A Promotes osteogenic differentiation by increasing opg/rankl ratio in stem cells from human exfoliated deciduous teeth (SHED). J Tissue Eng Regen Med 2018;12:1856-66.

13. Xuan K, Li B, Guo H, et al. Deciduous autologous tooth stem cells regenerate dental pulp after implantation into injured teeth. Sci Transl Med 2018;10:eaaf3227.

14. Shi X, Mao J, Liu Y. Pulp stem cells derived from human permanent and deciduous teeth: Biological characteristics and therapeutic applications. Stem Cells Transl Med 2020;9:445-64.

15. Bernardi L, Luisi SB, Fernandes R, et al. The isolation of stem cells from human deciduous teeth pulp is related to the physiological process of resorption. J Endod 2011;37:973-9.

16. Taguchi T, Yanagi Y, Yoshimaru K, et al. Regenerative medicine using stem cells from human exfoliated

doi: $10.21037 /$ sci-2020-039

Cite this article as: Bhandary $M$, Rao S, Shetty AV, Kumar BM, Hegde AM, Chhabra R. Comparison of stem cells from human exfoliated deciduous posterior teeth with varying levels of root resorption. Stem Cell Investig 2021;8:15. deciduous teeth (SHED): a promising new treatment in pediatric surgery. Surg Today 2019;49:316-22.

17. Nakajima K, Kunimatsu R, Ando K, et al. Success rates in isolating mesenchymal stem cells from permanent and deciduous teeth. Sci Rep 2019;9:16764.

18. Kerkis I, Kerkis A, Dozortsev D, et al. Isolation and characterization of a population of immature dental pulp stem cells expressing OCT-4 and other embryonic stem cell markers. Cells Tissues Organs 2006;184:105-16.

19. Hilkens P, Gervois P, Fanton Y, et al. Effect of isolation methodology on stem cell properties and multilineage differentiation potential of human dental pulp stem cells. Cell Tissue Res 2013;353:65-78.

20. Bakopoulou A, Leyhausen G, Volk J, et al. Assessment of the impact of two different isolation methods on the osteo/ odontogenic differentiation potential of human dental stem cells derived from deciduous teeth. Calcif Tissue Int 2011;88:130-41.

21. Suchánek J, Visek B, Soukup T, et al. Stem cells from human exfoliated deciduous teeth-isolation, long term cultivation and phenotypical analysis. Acta Medica (Hradec Kralove) 2010;53:93-9.

22. Boxall SA, Jones E. Markers for characterization of bone marrow multipotential stromal cells. Stem Cells Int 2012;2012:975871.

23. Liu J, Yu F, Sun Y, et al. Concise Reviews: Characteristics and Potential Applications of Human Dental Tissue Derived Mesenchymal Stem Cells. Stem Cells 2015;33:627-38.

24. Isobe Y, Koyama N, Nakao K, et al. Comparison of human mesenchymal stem cells derived from bone marrow, synovial fluid, adult dental pulp, and exfoliated deciduous tooth pulp. Int J Oral Maxillofac Surg 2016;45:124-31. 